\title{
Prevalence and outcome of teenage hospital births at the buea health district, South West Region, Cameroon
}

Thomas Obinchemti Egbe ${ }^{1,2^{*}} \mathbb{D}$, Amadeus Omeichu ${ }^{4}$, Gregory Edie Halle-Ekane ${ }^{1,2}$, Charlotte Nguefack Tchente ${ }^{1,3}$, Eta-Nkongho Egbe ${ }^{5}$ and Jean-Francois Oury ${ }^{6}$

\begin{abstract}
Background: Teenage pregnancy is a high-risk condition that requires skilled antenatal care for good outcome. World estimates in 2008 report about 16 million births to adolescent mothers, most of them occurring in low and middle-income countries. In Cameroon, about $12 \%$ of all births are to adolescent mothers. This study determines the prevalence of hospital teenage deliveries in the Buea Health District and compares the delivery outcomes and demographic characteristics between pregnant teenage mothers (14-19) and adult mothers (20-29 years). We also identify factors associated with adverse pregnancy outcomes.
\end{abstract}

Methods: We undertook a retrospective study of case files of patients who gave birth in the Buea Regional Hospital during the period 2009-2012, to determine the prevalence of hospital-delivered teenage pregnancies in the BHR. We also undertook a, cross-sectional study to compare the outcomes of 148 singleton adolescent births with 360 adult births in three health facilities in the Buea Health District during the period March 1 to August 31, 2013.

Results: The prevalence of teenage births was $13.3 \%$. The adverse fetal outcomes imputable to adolescent births were low birth weight $(<2,500 \mathrm{~g})(\mathrm{OR}, 2.79 ; 95 \% \mathrm{Cl}, 1.28-6.09)$, preterm babies ( $<37$ weeks) $(\mathrm{OR}: 1.85 ; 95 \% \mathrm{Cl}$, 1.01-3.41), low 5 min Apgar score < 7 (OR: 1.66; $95 \%$ Cl, 0.91-3.0). Adverse maternal outcomes associated with teenage pregnancies were mainly perineal tear $(\mathrm{OR}, 1.6 ; 95 \% \mathrm{Cl}, 0.95-2.7)$. Teenage births were not discovered in any significant way to cause preeclampsia/eclampsia, episiotomy, premature rupture of membranes and caesarean section. Maternal factors like age and gravidity were discovered to lead to adverse fetal outcomes in adolescents, while maternal factors like age, unemployment, marital status and gravidity were, for their part, directly responsible for adverse maternal outcomes in adolescents.

Conclusion: Teenage pregnancies are quite prevalent in the Buea Health District, and hospital delivery common. Adolescent pregnancies are more likely to lead to adverse fetal and maternal outcomes than adult pregnancies.

Keywords: Teenage/adolescent pregnancy, Prevalence, Perinatal outcomes, Low birth weight, Preterm, Perineal tear

\footnotetext{
*Correspondence: obinchemti@yahoo.com; toegbe@gmail.com; tom.egbe@outlook.com

${ }^{1}$ Department of Obstetrics and Gynecology, Douala General Hospital, Box 4856, Douala, Cameroon

${ }^{2}$ Faculty of Health Science, University of Buea, Box 63, Buea, Cameroon

Full list of author information is available at the end of the article
} 


\section{Background}

According to the World Health Organization, teenage or adolescent pregnancy is a pregnancy occurring in girls aged $10-19$ [1]. Teenage pregnancies constitute a serious health and social problem worldwide [2-4]. World estimates in 2008 report about 16 million births to adolescent mothers, most of them occurring in low and middle-income countries [5-7]. Among the social consequences of adolescent pregnancies are school drop-out, juvenile violence, suicide and sometimes homicide [6, 7].

Most studies establish a cause-and-effect relationship between teenage pregnancy and inadequate antenatal care [8-10], low birth weight, and preterm birth $[5,6,11]$. On the hand, such a relationship is less obvious in adverse pregnancy outcomes such as preeclampsia, cesarean delivery, vaginal instrumental delivery and postpartum hemorrhage [12].

Adolescent pregnancy constitutes a public health problem in Cameroon: $12 \%$ and $9.3 \%$ of all deliveries at the University Teaching Hospital (CHU) and Central Hospital Yaoundé respectively, are teenage [12-14]. Cameroon has one of the highest adolescent fertility rates in West and Central Africa. According to data collected in 2004 as part of the DHS, $22.7 \%$ of adolescents under 20 were mothers of at least one child [15]. Cameroon's adolescent fertility rate of 138 births per 1000 women aged $<19$ is the highest in Central Africa. However, the country's adolescent pregnancy rate is difficult to assess accurately, not least because national statistics on legal abortion are unreliable. They are so because of the wide differences in the local application of the law, and the discrepancies in public health data from one region of Cameroon to the other [15]. Statistics from the Social Welfare Centre in Buea, South West Region (SWR), Cameroon indicate that $5 \%$ of girls in Buea terminate schooling every academic year because of pregnancy [16].

The aim of this study is threefold; namely, to 1) determine the prevalence of adolescent deliveries in the Buea Health District; 2) assess the effects of adolescent births on both mother and child; and 3) compare the effects of demographic characteristics (age, marital status, education) on delivery outcomes in teenage and adult pregnancies.

\section{Methods}

\section{Study design}

This was a cross-sectional study with retrospective and prospective phases.

\section{Study area}

Buea is found in Fako Division in the South West Region of Cameroon. It covers a total surface area of 870 square $\mathrm{km}$ (Fig. 1). It has an equatorial climate, and temperatures range between $20-28{ }^{\circ} \mathrm{C}$. The town experiences two major seasons; a rainy season that begins in March and ends in October, and a dry season that begins in November and ends in February. Annual rainfall varies from 3000 to $5000 \mathrm{~mm}$.

\section{Study setting}

The study was carried out in the Buea Regional Hospital (BRH), the Muea Health Centre, and the Buea Town Health Centre. BRH is a secondary care centre and the Muea Health Centre and the Buea town Health Centre both primary care centers. The Buea Health District was created in 1995 and has an estimated population of 76272. Midwives and state registered or assistant nurses carried out all deliveries in the centers under study while Obstetricians or General Practitioners did caesarean deliveries.

The study was conducted in two phases: a retrospective study carried out over a period of one month (February $1^{\text {st }}$ to $\left.28^{\text {th }}, 2013\right)$, and a prospective cross-sectional analytic case-control study carried out over a period of 6 months (March 1 to August 31, 2013).

All nulliparous teenagers aged 14-19 with a singleton pregnancy who delivered in the above-mentioned health facilities during the study period were enrolled as cases. The comparison group was taken among nulliparous women aged between 20 and 29, with a singleton pregnancy, and who delivered during the same period.

Excluded from the study were women with a history of any medical condition prior to the current pregnancy (e.g. hypertension, diabetes mellitus, or any cardiac, renal, endocrine or autoimmune diseases). Also excluded were women with no delivery records, women with pregnancies less than 28 weeks gestation. Adolescents $<14$ were also excluded from the study given that they were particularly at risk because of immaturity of the pelvis. Nulliparous women above 30 and multifetal pregnancies were also excluded because they were already in the group of high-risk pregnancies (advanced maternal age in primigravida, and multifetal pregnancies in primigravida, respectively). Finally, women with any perinatal complication occurring after 48 hours were also excluded from the study.

\section{Sampling of participants}

The Buea Health District comprises seven health areas that in turn have several maternity units. Of these seven health areas, five were selected randomly by balloting. For the retrospective study, each health area represented a stratum. Registers of the antenatal care department of each health facility were exploited. Count was kept of newly-registered teenagers who consulted and delivered during the study period. Adult women who delivered during the same period comprised the control 


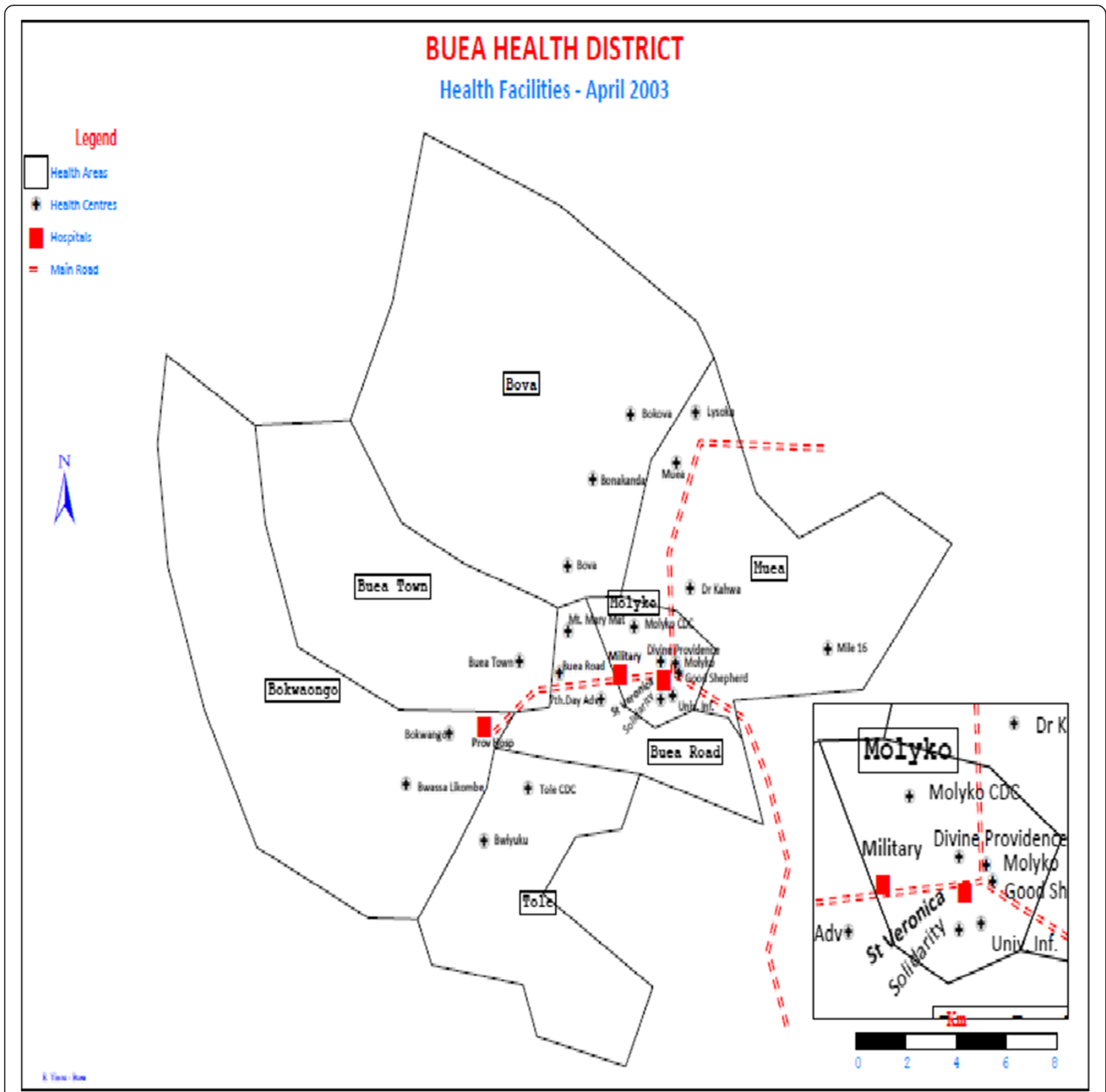

Fig. 1 Buea Health District of the South West Region. Source: UPEC 2009

group. After this phase, it was observed that, of the five health areas studied, three (Muea, Buea Town and Bokwango) handled most of the deliveries. The prospective cross-sectional analytic study was conducted in three health facilities within these health areas; namely, the Muea District Hospital, the Integrated Health Center Buea Town, and the Buea Regional Hospital. The participants in the selected health institutions were enrolled on admission for labor, interviewed with pre-tested questionnaires, and followed up till after delivery.

\section{Calculation of sample size}

Sample size was calculated using the WHO-steps approach [17]. The minimum sample size was $S=384$. A total of 508 participants (148 adolescents and 360 control) were enrolled for the study.

\section{Study procedure}

After signing an informed consent form, participants were administered a pre-tested survey questionnaire. Socio-demographic information, mainly maternal age, gravidity, religion, marital status, number of antenatal 
visits, employment status and level of education, was obtained, as was information on maternal and fetal outcomes. Gestational age of pregnancy was derived from the last normal menstrual period. Occasionally we relied on the first trimester ultrasound scan in patients who came for ANC early in pregnancy.

The following maternal outcomes were used to compare between the cases and controls: preeclampsia-eclampsia, premature rupture of membranes, placenta previa, placenta abruption, perineal tear, and episiotomy. We did not record the degree of perineal tears because of inconsistencies in the classification across the different health facilities.

Fetal and neonatal outcomes compared between the two groups were prematurity, low birth weight, post term, 5 min Apgar scores $<7$, stillbirth, and neonatal death. For the retrospective study, authorization to access medical records of patients was obtained from the directors of health facilities involved in the study.

\section{Ethical considerations}

Ethical clearance was obtained from the Institutional Review Board (IRB) of the Faculty of Health Sciences (FHS), University of Buea; and Administrative authorization from the Regional Delegation of Public Health for the SWR.

\section{Data management and analysis}

Data analysis was with Epi-Info version 7. Descriptive statistics was depicted using absolute numbers and simple percentages as appropriate. Regarding the cross sectional study, the frequencies for the entire variable were calculated and expressed as percentages of the total sample size. A bivariate analysis of categorical variables was done using Chi-square and Fisher's exact tests (where appropriate) to compare between predictor variables and outcome variables. Univariable analysis was done by Mantel Haenszel method to compare predictor variables to the outcome. The results were reported as odd ratios (OR) together with their $95 \%$ confidence intervals (CI). Multivariable analysis was done using logistic regressions, and only variables with a significance threshold of less than 0.1 were included in the final model. Results were reported as adjusted OR together with their $95 \%$ CI. Measure of association was considered statistically significant at a two-tailed p-value when $P<0.05$.

\section{Results}

During the period 2010 - 2013 a total of 6564 women were registered for ANC at the BHD. Among this group, $13.32 \%(874 / 6564)$ were teenagers.

Out of the 508 participants in the prospective study, $29.1 \%(148 / 508)$ were pregnant. Most participants, $73.6 \%(374 / 508)$ had a secondary level of education, and only $19.3 \%$ had undergone tertiary education. Most of the participants, $96.9 \%(492 / 508)$ were Christians. Among the study participants, $47.2 \%(240 / 508)$ had employment, $58.7 \%(298 / 508)$ were married, while $43.7 \%(222 / 508)$ were nulliparous. Two hundred and ninety-six participants $(58.3 \%)$ attended 4 or more ANC visits throughout pregnancy. $52.4 \%(266 / 508)$ participants had adverse perinatal pregnancy outcomes, while $43.2 \%$ had adverse fetal outcomes. Of the 266 participants with adverse outcomes, 211 had adverse maternal outcomes.

\section{Comparison of socio-demographic characteristics}

Table 1: It was observed that, the level of education was 3.7 times higher among adult mothers $(P<0.001)$ and adults were also 3.1 times more likely to be employed $(P<0.001)$. Furthermore, adults were 3.8 times more likely to be married and 3.0 times more likely to have more than one child $(P<0.001)$ compared to the teenage group.

Religion and antenatal care (ANC) visits did not differ amongst the two groups $(P<0.2$ and $P<0.4$, respectively).

\section{Comparison of fetal outcomes}

Table 2: Teenage mothers were more likely to have preterm babies (OR, 1.9; 95 \% CI, 1.0-3.4: $P<0.03$ ), LBW infants (OR, 2.8; $95 \% \mathrm{CI}, 1.3-6.1: P<0.006)$ and low 5 min Apgar scores (OR, 1.7; 95 \% CI, 0.9-3.0: $P<0.05$ ) than adult mothers. On the other hand, the rates of neonatal deaths, stillbirths and post-terms were insignificant in both groups. Overall, there was more than a twofold increase in the likelihood of adverse fetal outcomes among teenage mothers (OR, 2.1; $95 \% \mathrm{CI}$, 1.4-3.2: $P<0.001$ ).

\section{Comparison of maternal outcomes}

Table 3: Adolescent mothers had a significantly higher rate of perineal tear compared with the adult population (OR, 1.59; 95 \% CI, 0.95-2.67: $\mathrm{P}=0.04$ ). However, there were no significant differences between the two groups in the frequency of cesarean sections, eclampsia, preeclampsia, placenta previa, PROM and episiotomy. On the whole, there was a 1.5 times increase in the likelihood of adverse maternal outcomes among teenage mothers (OR, 1.5; 95 \% CI, 1.3-2.4: $\mathrm{P}=0.03$ )

\section{Comparison of demographic parameters with adverse fetal outcomes}

Table 4: Age (aOR, 2.79; $95 \% \mathrm{CI}, 0.05-0.83: P<006)$ and gravidity (aOR, 9.08; $95 \%$ CI 3.21-25.69) were significant factors in adverse fetal outcomes. Adverse fetal outcomes reduced with increasing maternal age and gravidity. 
Table 1 Comparison of socio-demographic variables among teenagers (14-19) and adult group (20-29) years

\begin{tabular}{|c|c|c|c|c|}
\hline Variables & $\begin{array}{l}\text { Teenagers }(14-19 \text { years) } \\
\text { Cases }(n=148) N(\%)\end{array}$ & $\begin{array}{l}\text { Control group (20-29 years) } \\
\text { Cases }(n=360) N(\%)\end{array}$ & OR (95 \% Cl) & P-value \\
\hline \multicolumn{5}{|l|}{ Education (years) } \\
\hline Primary(6) & $16(10.8 \%)$ & $20(5.6 \%)$ & $3.7(2.1-5.5)$ & $<0.001$ \\
\hline Secondary (7-13) & 129(87.2 \%) & $245(68.1 \%)$ & & \\
\hline Tertiary $(\geq 14)$ & $3(2.0 \%)$ & $95(26.4 \%)$ & & \\
\hline \multicolumn{5}{|l|}{ Occupation } \\
\hline Employed & $43(10.8 \%)$ & $197(54.7 \%)$ & $3.1(2.0-4.7)$ & $<0.001$ \\
\hline Unemployed & 105(70.9 \%) & $163(45.3 \%)$ & & \\
\hline \multicolumn{5}{|l|}{ Marital status } \\
\hline Married & $53(35.8 \%)$ & $245(68.1 \%)$ & $3.8(2.6-5.7)$ & $<0.001$ \\
\hline Single & $95(64.2 \%)$ & $115(51.9 \%)$ & & \\
\hline \multicolumn{5}{|l|}{ Gravidity } \\
\hline$\geq 2$ & $40(27.0 \%)$ & $246(68.3 \%)$ & $3.0(2.3-4.9)$ & $<0.001$ \\
\hline 1 & 108(73.0 \%) & 114(31.7\%) & & \\
\hline \multicolumn{5}{|l|}{ Religion } \\
\hline Christian & $142(95.9 \%)$ & 350(97.2 \%) & $1.7(0.6-4.7)$ & $<0.23$ \\
\hline Muslim & $6(4.1 \%)$ & $10(2.8 \%)$ & & \\
\hline \multicolumn{5}{|l|}{ ANC } \\
\hline$\geq 4$ Visits & $60(40.5 \%)$ & $152(42.2 \%)$ & $1.02(0.7-4.6)$ & $<0.4$ \\
\hline $0-3$ Visits & $88(59.5 \%)$ & $208(57.8 \%)$ & & \\
\hline
\end{tabular}

Cl: Confidence interval

OR: Odds ratio

\section{Comparison of demographic parameters with adverse maternal outcomes}

Table 5: Age (aOR, 1.59; 95 \% CI, 0.95-2.67: $\mathrm{P}=0.04)$, employment (aOR, 0.48; $95 \% \mathrm{CI}, 0.29-0.82: \mathrm{P}=0.003)$, marital status (aOR, 0.58; $95 \% \mathrm{CI}, 0.36-0.96: \mathrm{P}=0.02)$ and gravidity (aOR, 9.08; $95 \% \mathrm{CI}, 3.21-25.69: P<0.001$ ) were significant factors in adverse maternal outcomes.

\section{Discussion}

Our study, set in the Buea Health District (BHD), a suburban region of Cameroon, sought to 1) determine the prevalence of adolescent hospital deliveries in the Buea Health District; 2) assess the effects of such births on both mother and child; and 3) compare demographic characteristics (age, marital status, education) between teenage mothers and comparison group of adults between 20-29.

The prevalence of teenage births in this study was $13.3 \%$. There were more adverse fetal and maternal outcomes among adolescent mothers between 14-19 than among adult mothers between 20-29. On the other hand, there was a close similarity between the demographic parameters and adverse outcomes in the two groups.

\section{Prevalence of teenage births}

The $13.3 \%$ prevalence of teenage pregnancies found among the study population fell within the $6-14 \%$ range reported in other studies in Sub-Saharan African countries [9, 18-21]. It was higher than those of a similar study in Yaoundé $[20,22]$ though lower than the rate observed in the study conducted by Tebeu PM at al. [19], Sulaiman S at al. [22], Shah N et al. [23]. This high prevalence could be attributed to differences in socioeconomic status, level of education and level of employment.

Low levels of education, unemployment and pre-marital adventures were discovered to be important contributory factors to teenage pregnancy. These findings corroborated those reported by other studies [24-27].

\section{Socio-demographic characteristics}

Reports concerning developing countries indicate an inverse relationship between education level and frequency of adolescent pregnancy and/or childbearing [28-31]. Regarding marital status, studies in low-income countries reported that most teenage pregnancies occurred within marriage and so did not occasion any social stigma [3]; but our study proved the contrary. We discovered instead that more teenage pregnancies occurred outside marriage than in it. This finding is confirmed by Kongnyuy J et al. and Ekachai $\mathrm{K}$ et al. [8, 32, 33]. Whatever contradiction there is between our study and those carried out in other low-income countries could be 
Table 2 Comparison of fetal outcome among teenagers (14-19 years) and adult group

\begin{tabular}{|c|c|c|c|c|}
\hline Parameters & $\begin{array}{l}\text { Teenagers ( }<20 \text { years }) \\
(\mathrm{n}=148) \mathrm{N}(\%)\end{array}$ & $\begin{array}{l}\text { Control group (20-29 years) } \\
(n=360) N(\%)\end{array}$ & OR $(95 \% \mathrm{Cl})$ & P-value \\
\hline \multicolumn{5}{|c|}{ Fetal Outcome } \\
\hline Adverse & $58(39.2 \%)$ & $84(23.3 \%)$ & $2.1(1.40-3.2)$ & $<0.001$ \\
\hline Normal & $90(60.8 \%)$ & $276(76.7 \%)$ & & \\
\hline \multicolumn{5}{|l|}{ Preterm } \\
\hline Yes & $20(13.5 \%)$ & $28(7.8 \%)$ & $1.9(1.0-3.4)$ & 0.03 \\
\hline No & $128(86.5 \%)$ & $332(92.2 \%)$ & & \\
\hline \multicolumn{5}{|c|}{ Low birthweight(<2500 g) } \\
\hline Yes & 14(9.5 \%) & 13(3.6 \%) & $2.8(1.3-6.1)$ & 0.006 \\
\hline No & 134(90.5\%) & $347(96.4 \%)$ & & \\
\hline \multicolumn{5}{|l|}{ Post term } \\
\hline Yes & $4(2.7 \%)$ & $5(1.4 \%)$ & $2.0(0.5-7.5)$ & 0.2 \\
\hline No & 144(97.3\%) & 355(98.6 \%) & & \\
\hline \multicolumn{5}{|c|}{5 min APGAR score $<7$} \\
\hline Yes & $20(13.5 \%)$ & $31(8.6 \%)$ & $1.7(0.9-3.0)$ & 0.05 \\
\hline No & $128(86.5 \%)$ & 329(91.4 \%) & & \\
\hline \multicolumn{5}{|l|}{ Still birth } \\
\hline Yes & $8(5.4 \%)$ & $10(2.8 \%)$ & $2.0(0.8-5.2)$ & 0.08 \\
\hline No & $140(94.6 \%)$ & $350(97.2 \%)$ & & \\
\hline \multicolumn{5}{|c|}{ Neonatal death } \\
\hline Yes & $6(41.1 \%)$ & $9(2.5 \%)$ & $1.7(0.6-4.7)$ & 0.2 \\
\hline No & 142(95.9\%) & $351(97.5 \%)$ & & \\
\hline \multicolumn{5}{|c|}{ Malformation } \\
\hline Yes & $1(0.7 \%)$ & $2(0.6 \%)$ & $1.2(0.6-4.7)$ & 0.2 \\
\hline No & $128(86.5 \%)$ & $318(88.3 \%)$ & & \\
\hline \multicolumn{5}{|c|}{ Placenta abruption } \\
\hline Yes & $4(2.7 \%)$ & $5(1.4 \%)$ & $2.0(0.5-7.5)$ & 0.17 \\
\hline No & $146(99.3 \%)$ & $358(99.4 \%)$ & & \\
\hline
\end{tabular}

OR: Odds ratio

explained by the small sample size in our case and the socio-cultural differences from one situation to the other. Our study also shows that $73 \%$ of adolescent pregnancies were in their first gestation while in the control group the percentage was 31.7.

A non-statistical significant trend was observed among 148 teenage mothers who gave birth during the study period. $59.5 \%(88 / 146)$ of them had inappropriate antenatal care (less than 4 ANC). This trend was similar to that reported in other studies [32, 33]. Generally, it has been reported that about $72.8 \%$ adolescents compared with $89.29 \%$ women aged 20-29 attended four or more ANCs during pregnancy in Cameroon [32]. In the Philippines, among pregnant girls $<18$, only $29 \%$ received antenatal care, compared with $81 \%$ among women aged 20-30 [11, 18]. This could be explained by the fact that most of the adolescents were unmarried, unemployed and less educated. Complications among adolescents were attributed to insufficient or inadequate antenatal care. Most of the health problems associated with adolescent pregnancies and childbearing could be prevented and controlled with timely and appropriate care during and after the pregnancy $[34,35]$.

\section{Maternal and fetal outcomes of teenage pregnancies}

This study found more adverse maternal and fetal outcomes among adolescent mothers (14-19) than among adult women (20-29), a situation very much similar to those reported in literature on the subject $[33,36,37]$. However, our findings differ from those of McAnarney ER et al., [38], Elster A [39]. This difference can be explained by the fact that the various 
Table 3 Comparison of maternal outcome among teenagers (14-19 years) and adult group

\begin{tabular}{|c|c|c|c|c|c|}
\hline Parameters & Frequency(Percentage) & $\begin{array}{l}\text { Teenagers (14-19years) } \\
(n=148) N(\%)\end{array}$ & $\begin{array}{l}\text { Control group (20-29 years) } \\
(n=360) N(\%)\end{array}$ & OR $(95 \% \mathrm{Cl})$ & P-value \\
\hline \multicolumn{6}{|c|}{ Maternal Outcome } \\
\hline Adverse & & $64(43.2 \%)$ & $123(34.2 \%)$ & $1.5(1.0-2.2)$ & 0.03 \\
\hline Normal & & $84(56.8 \%)$ & $237(65.8 \%)$ & & \\
\hline \multicolumn{6}{|c|}{ Pre-eclampsia } \\
\hline Yes & $10(4.7 \%)$ & $3(2.0 \%)$ & $7(1.9 \%)$ & $1.0(0.3-4.1)$ & 0.5 \\
\hline No & & 145(98.0 \%) & 353(98.1\%) & & \\
\hline \multicolumn{6}{|l|}{ Eclampsia } \\
\hline Yes & $06(2.8 \%)$ & $3(2.0 \%)$ & $3(0.8 \%)$ & $2.5(0.5-12.3)$ & 0.15 \\
\hline No & & $145(98.0 \%)$ & $357(99.2 \%)$ & & \\
\hline \multicolumn{6}{|l|}{ PROM } \\
\hline Yes & $33(15.6 \%)$ & $11(7.4 \%)$ & $22(6.1 \%)$ & $1.2(0.6-2.6)$ & 0.3 \\
\hline No & & 137(92.6 \%) & $338(93.9 \%)$ & & \\
\hline \multicolumn{6}{|c|}{ Placenta previa } \\
\hline Yes & $05(2.4 \%)$ & $1(0.7 \%)$ & $4(1.1 \%)$ & $06(0.1-5.5)$ & 0.4 \\
\hline No & & 147(99.3 \%) & $356(98.9 \%)$ & & \\
\hline \multicolumn{6}{|l|}{ Perineal tear } \\
\hline Yes & 74(35.1\%) & $28(18.9 \%)$ & $46(12.8 \%)$ & $1.6(1.0-2.7)$ & 0.04 \\
\hline No & & $120(81.1 \%)$ & $314(87.2 \%)$ & & \\
\hline \multicolumn{6}{|l|}{ Episiotomy } \\
\hline Yes & $12(5.7 \%)$ & $5(3.4 \%)$ & $7(1.9 \%)$ & $1.8(0.6-5.7)$ & 0.2 \\
\hline No & & 143(97.3 \%) & 353(98.1\%) & & \\
\hline \multicolumn{6}{|c|}{ Cesarean section } \\
\hline Yes & $62(29.4 \%)$ & $20(13.5 \%)$ & $42(11.7 \%)$ & $1.2(0.7-2.1)$ & 0.3 \\
\hline
\end{tabular}

adolescent populations tend to be tributary to different socio-economic conditions and institutional constraints. Besides, the sample sizes are often very uneven.

Many studies have reported that adolescents are exposed to such adverse fetal outcomes as fetal death, neonatal death, low birth weight, IUGR and prematurity [40-42]. This study shows that pregnant adolescents had higher rates of LBW infants, premature babies and lower 5 min Apgar scores $(<7)$ than adult mothers. This tied in with other studies $[19,24,41]$. However, the rates of post-term, neonatal deaths and stillbirths were similar between the two groups [23]. This may be explained by

Table 4 Significant demographic parameters associated with adverse outcome

\begin{tabular}{lll}
\hline Parameter & Adjusted odd ratio $(95 \% \mathrm{Cl})$ & P-value \\
\hline Age (years) & $2.79(0.05-0.83)$ & $<0.006$ \\
Gravidity & $9.08(3.21-25.69)$ & $<0.001$ \\
\hline
\end{tabular}

Cl: Confidence interval the fact that our study was not designed to detect rare outcomes and risk factors such as smoking or alcohol abuse in our adolescent population.

There was a significantly higher rate of perineal tears (18.9\%) among adolescent mothers in this study. This finding agrees with previous studies $[14,43,44]$ but differs with them when it comes to preeclampsia/eclampsia, episiotomy, cesarean deliveries and PROM. Studies in Turkey confirm our position [45]. The widely-held

Table 5 Significant demographic parameters associated with adverse maternal outcome

\begin{tabular}{lll}
\hline Parameter & Adjusted odd ratio $(95 \% \mathrm{Cl})$ & P-value \\
\hline Age (years) & $1.59(0.95-2.67)$ & 0.041 \\
Employment & $0.48(0.29-0.82)$ & 0.003 \\
Marital status & $0.58(0.36-0.96)$ & 0.017 \\
Gravidity & $9.08(3.21-25.69)$ & $<0.001$ \\
\hline
\end{tabular}

Cl: Confidence Interval 
belief that the biological immaturity of the adolescent pelvis causes cephalo-pelvic disproportion (CPD) leading to increased cesarean sections [46] was not confirmed by this study, probably because of the small sample size studied. Similarly, Imir did not find higher cesarean sections among adolescents than in the adult control group [45]. The controversy over this finding may be explained by the fact that adolescents generally give birth to small-size babies and so CPD is not necessarily a major problem in this age group. But Ogelle $\mathrm{OM}$ et al. found an increase in cesarean sections among adolescents in Nigeria [47]. It was also noted that although cesarean delivery was not statistically significant among adolescents, a greater proportion of them, $13.5 \%$ underwent cesarean delivery than women in the comparison group (11.7\%) and the main indication was CPD.

It has been reported that teenage mothers were more likely to die from pregnancy and delivery complications [48-51]. However, we did not record any maternal deaths among teenage mothers in this study.

Our study noted that maternal age and gravidity had significant bearings on fetal outcomes. Furthermore, there was a nine-fold possibility of having adverse fetal outcomes among teenage mothers. Similar findings were reported by Kongnyuy et al. [32]. This may be explained by the fact that the small birth canal, rigid perineum and inappropriate psychological preparation for labor and delivery usually encountered among teenage primigravidas could lead to prolonged labor, with consequent fetal distress and low Apgar scores. Marital status had little or no effect on fetal outcomes, especially adverse, in our study.

Maternal age, marital status, unemployment and gravidity were seen to impact significantly on maternal outcomes. Gravidity was about nine times more of a contributory factor in maternal outcomes. The rigid perineum of primiparous mothers could be responsible for the perineal tears. The frequently inadequate prenatal care in adolescents has been reported previously $[17,32,33]$ and may be explained by poverty, inadequate support from families and community, and even the judgmental attitude in prenatal care. Another study in Nigeria showed that unemployment impacted maternal outcomes [20].

There is very little health insurance coverage in Cameroon. Only a thin minority of company workers enjoy it. Therefore, most teenage and even adult pregnant women shoulder the cost of their antenatal care and delivery (including transportation, consultation, laboratory tests, and medication). This has usually been a burden to these patients who generally have low purchasing power or, as is often the case, no purchasing power at all.

\section{Study limitations}

This was a hospital-based study with a small sample size; as such, we were not able to study the pregnancy outcomes of teenage mothers in the entire BHR. Socio-economic, sociocultural and psychological factors that could be an important determinant in pregnancy outcomes were not investigated in this study. There was no significant scope for follow-up, so outcomes like neonatal infections could not be investigated. We also did not study the effect of sex education among the teenage group.

\section{Conclusion}

There was a high prevalence of teenage pregnancy in the BHD. Adolescent pregnancies were directly responsible for both maternal and fetal adverse outcomes.

The adverse fetal outcomes attributed to adolescent pregnancies were low birth rate $(<2,500 \mathrm{~g})$, low $5 \mathrm{~min}$ Apgar score $(<7)$ and preterm births $(<37$ weeks). The rate of stillbirths and post-term deliveries was not significantly different between adolescent and adult mothers.

The adverse maternal outcomes caused by adolescent pregnancies were mainly perineal tear. Incidence of preeclampsia/eclampsia, episiotomy, placenta previa, cesarean section and PROM was not significantly different between adolescents and adult women.

Teenage mothers were more likely to be unemployed, unmarried and less educated than the control group. Demographic factors such as age, gravidity, marital status, and occupational status were contributory factors to adverse pregnancy outcomes.

\section{Recommendation}

Similar studies should be carried out in other parts of Cameroon to obtain national statistics that could reveal the magnitude of the problem and so help policy makers in their search for curative strategies.

\section{Competing interests}

I declare that I have no competing interests.

\section{Authors' contributions}

TOE, GEHE and CNT conceptualized the study. AO and EE conducted the data collection. TOE and AO conducted the data analysis. TOE wrote the manuscript, JFO supervised and proofread the manuscript. All the co-authors gave advice on presentation of the results and editing of the text, and approved the final manuscript.

\section{Authors' information}

Thomas Obinchemti Egbe, MD: Senior lecturer of Obstetrics and Gynecology Charlotte Nguefack Tchente, MD: Senior lecturer of Obstetrics and

Gynecology

Gregory Edie Halle Ekane, MD: Senior lecturer of Obstetrics and Gynecology

Amadeus Omeichu, MD: General Practitioner

Eta-Nkongho Egbe, MD: General Practitioner

Jean Francois Oury, MD: Professor of Obstetrics and Gynecology 


\section{Acknowledgements}

We thank the nurses of the health facilities under study for the assistance they gave us throughout this study. Special thanks to Dr. Temfack for the advice he gave us during the statistical analysis.

\section{Author details}

'Department of Obstetrics and Gynecology, Douala General Hospital, Box 4856, Douala, Cameroon. ${ }^{2}$ Faculty of Health Science, University of Buea, Box 63, Buea, Cameroon. ${ }^{3}$ Faculty of Medicine and Pharmaceutical Science, University of Douala, Douala, Cameroon. ${ }^{4}$ District Hospital Mamfe, South West Region, Mamfe, Cameroon. ${ }^{5}$ District Hospital Poli, North Region, Poli, Cameroon. ${ }^{6}$ Department of Obstetrics and Gynecology, Robert Debré Hospital, 75935 Cedex 19 Paris, France.

\section{Received: 11 December 2015 Accepted: 15 December 2015} Published online: 23 December 2015

\section{References}

1. Okogbenin SA, Okpere EE. Age and reproductive outcome. Clin Obstet. 2004:3:398-400 [Uniben Press].

2. Akinola SE, Manne NC, Archibong El, Sobande AA. Teenagers obstetric performance. Saudi Med J. 2001;22:580-4.

3. Ekanem AD, Etuk SJ, Archibong El. Socio-economic background of pregnant teenagers in Calabar, Nigeria. Int J Soc Sci Public Policy. 2001:4:235-42.

4. Moini A, Riazi K, Mehrparvar AH. Pregnancy and labor complications in teenagers in Tehran. Int J Gynaecol Obstet Off Organ Int Fed Gynaecol Obstet. 2002;78:245-7.

5. Ekwo EE, Moawad A. Maternal age and preterm births in a black population. Paediatr Perinat Epidemiol. 2000;14:145-51.

6. Ziadeh S. Obstetric outcome of teenage pregnancies in North Jordan. Arch Gynecol Obstet. 2001;265:26-9.

7. Lao TT, Ho LF. The obstetric implications of teenage pregnancy. Hum Reprod Oxf Engl. 1997:12:2303-5.

8. Kovavisarach E, Chairaj S, Tosang K, Asavapiriyanont S, Chotigeat U. Outcome of teenage pregnancy in Rajavithi Hospital. Med J Med Assoc Thail. 2010;93:1.

9. Iklaki CU, Inaku JU, Ekabua JE, Ekanem El, Udo AE. Perinatal Outcome in Unbooked Teenage Pregnancies in the University of Calabar Teaching Hospital, Calabar, Nigeria. Int Sch Res Not. 2012;2012:e246983.

10. Maliki AE. The Effect of Teenage Pregnancy on Adolescents in Amassoma Community of Southern ljaw Local Government Area of Bayelsa State. Asian Soc Sci. 2012;8:p62.

11. Reime B, Schücking BA, Wenzlaff P. Reproductive outcomes in adolescents who had a previous birth or an induced abortion compared to adolescents first pregnancies. BMC Pregnancy Childbirth. 2008:8:4

12. Liran D, Vardi IS, Sergienko $R$, Sheiner E. Adverse perinatal outcome in teenage pregnancies: is it all due to lack of prenatal care and ethnicity? J Matern Fetal Neonatal Med. 2013:26:469-72.

13. Ngowa JDK, Pisoh WD. Obstetrical and Perinatal Outcomes of Adolescent Pregnancies in Cameroon: A Retrospective Cohort Study at the Yaoundé General Hospital. SciRes. 2015;88-93.

14. Fouelifack FY, Tameh TY, Mbong EN, Nana PN, Fouedjio JH, Fouogue JT, et al. Outcome of deliveries among adolescent girls at the Yaoundé central hospital. BMC Pregnancy Childbirth. 2014:14:102.

15. Jazet E, Dzossa A. DHS Cameroon 2004. Caractéristiques des femmes et des homes enquêtés [monograph on the Internet]," 2004,. 2004.

16. Fomenky E. Teenage Pregnancies Hinder Girl Education. 2008.

17. Lwanga SK, Lemeshow S. Sample size determination in health studies: a practical manual. 1991

18. Chandra-Mouli V, Alma VC, Michaud PA. WHO Guidelines on Preventing Early Pregnancy and Poor Reproductive Outcomes among Adolescents in Developing Countries. J Adolesc Health. 2013;52:517-22.

19. Tebeu PM, Kemfang JD, Sandjong DI, Kongnyuy E, Halle G, Doh AS. Geographic Distribution of Childbirth among Adolescents in Cameroon from 2003 to 2005. Obstet Gynecol Int. 2010;2010.

20. Nkwabong E, Fomulu JN. Adolescent pregnancies and deliveries: problems encountered. Trop Doct. 2009;39:9-11.

21. Amoran OE. A comparative analysis of predictors of teenage pregnancy and its prevention in a rural town in Western Nigeria. Int J Equity Health. 2012;11:37.
22. Tebeu PM, Tantchou J, Obama Abena MT, Mevoula Onala D, Leke RJ. Delivery outcome of adolescents in Far North Cameroon. Rev Médicale Liège. 2006;61:124-7.

23. Sulaiman S, Othman S, Razali N, Hassan J. Obstetric and perinatal outcome in teenage pregnancies. South Afr J Obstet Gynaecol. 2013;19:77-80.

24. Shah N, Rohra DK, Shuja S, Liaqat NF, Solangi NA, Kumar K, et al. Comparision of obstetric outcome among teenage and non-teenage mothers from three tertiary care hospitals of Sindh, Pakistan. JPMA J Pak Med Assoc. 2011:61:963-7.

25. Lee MC, Suhng L-A, Lu T-H, Chou M-C. Association of parental characteristics with adverse outcomes of adolescent pregnancy. Fam Pract. 1998;15:336-42

26. Coley RL, Chase-Lansdale PL. Adolescent pregnancy and parenthood: recent evidence and future directions. Am Psychol. 1998;53:152.

27. Brooks-Gunn J, Duncan GJ. The effects of poverty on children. Future Child. 1997;55-71.

28. Omar K, Hasim S, Muhammad NA, Jaffar A, Hashim SM, Siraj HH. Adolescent pregnancy outcomes and risk factors in Malaysia. Int J Gynecol Obstet. 2010;111:220-3.

29. Singh S. Adolescent childbearing in developing countries: a global review. Stud Fam Plann. 1998:117-136.

30. Singh S, Darroch JE. Adolescent pregnancy and childbearing: levels and trends in developed countries. Fam Plann Perspect. 2000;14-23.

31. Singh S, Sedgh G, Hussain R. Unintended pregnancy: worldwide levels, trends, and outcomes. Stud Fam Plann. 2010:41:241-50.

32. Oner S, Yapici G, Kurt AO, Sasmaz T, Bugdayci R. The sociodemographic factors related with the adolescent pregnancy. Asian Pac J Reprod. 2012;1:135-41

33. Kongnyuy EJ, Nana PN, Fomulu N, Wiysonge SC, Kouam L, Doh AS. Adverse perinatal outcomes of adolescent pregnancies in Cameroon. Matern Child Health J. 2008;12:149-54.

34. Cornelius MD, Goldschmidt L, Willford JA, Leech SL, Larkby C, Day NL. Body size and intelligence in 6-year-olds: are offspring of teenage mothers at risk? Matern Child Health J. 2009;13:847-56.

35. Cornelius MD, Goldschmidt L, De Genna NM, Richardson GA, Leech SL, Day R. Improvement in intelligence test scores from 6 to 10 years in children of teenage mothers. J Dev Behav Pediatr JDBP. 2010;31:405-13.

36. Loto OM, Ezechi OC, Kalu BKE, Loto A, Ezechi L, Ogunniyi SO. Poor obstetric performance of teenagers: is it age- or quality of care-related? J Obstet Gynaecol J Inst Obstet Gynaecol. 2004:24:395-8.

37. Chibber R, Fouda M, Al-Hijji J, Al-Dossary M, Sadeq EH, Amen A, et al. Adverse pregnancy outcome among teenagers: A reality? J Obstet Gynaecol. 2014;34:297-300.

38. McAnarney ER, Hendee WR. Adolescent pregnancy and its consequences JAMA. 1989:262:74-7.

39. Elster $A B$. The effect of maternal age, parity, and prenatal care on perinatal outcome in adolescent mothers. Am J Obstet Gynecol. 1984;149:845-7.

40. Restrepo-Méndez MC, Barros AJD, Santos IS, Menezes AMB, Matijasevich A, Barros FC, et al. Childbearing during adolescence and offspring mortality: findings from three population-based cohorts in southern Brazil. BMC Public Health. 2011:11:781.

41. Chantrapanichkul P, Chawanpaiboon S. Adverse pregnancy outcomes in cases involving extremely young maternal age. Int I Gynaecol Obstet Off Organ Int Fed Gynaecol Obstet. 2013;120:160-4

42. Kuyumcuoglu U, Guzel Al, Celik Y. Comparison of the risk factors for adverse perinatal outcomes in adolescent age pregnancies and advanced age pregnancies. Ginekol Pol. 2012;83:33-7.

43. Legino LJ, Woods MP, Rayburn WF, McGoogan LS. Third- and fourth-degree perineal tears. 50 year's experience at a university hospital. J Reprod Med. 1988;33:423-6.

44. Sagili H, Pramya N, Prabhu K, Mascarenhas M, Reddi Rani P. Are teenage pregnancies at high risk? A comparison study in a developing country. Arch Gynecol Obstet. 2012;285:573-7

45. Imir GA, Çetin M, Balta Ö, Buyukayhan D, Cetin A. Perinatal Outcomes of Adolescent Pregnancies at a University Hospital in Turkey. J Turk-Ger Gynecol Assoc. 2008:9:71-4.

46. Peña E, Sánchez A, Solano L. Profile of nutritional risk in pregnant adolescents (in Spanish; Castilian). Archieves Latinoam Nutrition. 2003:53:141-9.

47. Ogelle OM, Eke AC, Okafor Cl, Mbamara SU, Obiechina NJ. Teenage pregnancies: a lingering obstetric problem in Nigeria. Niger J Med J Nat Assoc Resid Dr Niger. 2010;20:414-20. 
48. Blanc AK, Winfrey W, Ross J. New findings for maternal mortality age patterns: aggregated results for 38 countries. PLoS One. 2013;8:e59864.

49. Acharya DR, Bhattarai R, Poobalan A, van Teijlingen ER, Chapman G. Factors associated with teenage pregnancy in South Asia. 2014

50. Victora CG, Aquino EM, Do Carmo Leal M, Monteiro CA, Barros FC, Szwarcwald CL. Maternal and child health in Brazil: progress and challenges. Lancet. 2011;377:1863-76.

51. Gibbs CM, Wendt A, Peters $S$, Hogue CJ. The impact of early age at first childbirth on maternal and infant health. Paediatr Perinat Epidemiol. 2012;26:259-84

Submit your next manuscript to BioMed Central and we will help you at every step:

- We accept pre-submission inquiries

- Our selector tool helps you to find the most relevant journal

- We provide round the clock customer support

- Convenient online submission

- Thorough peer review

- Inclusion in PubMed and all major indexing services

- Maximum visibility for your research

Submit your manuscript at www.biomedcentral.com/submit
Biomed Central 